\title{
Spinal trabecular bone mineral content in patients with non-steroid treated rheumatoid arthritis
}

\author{
J E COMPSTON, 'E O CRAWLEY, ${ }^{2} \mathrm{C} \mathrm{EVANS}^{4}$ AND M M O'SULliVAN ${ }^{3}$
}

From the Department of ${ }^{I}$ Pathology, University of Wales College of Medicine, and the Departments of $\overline{0}$ ${ }^{2}$ Medical Physics, ${ }^{3}$ Rheumatology, and ${ }^{4}$ Radiology, University Hospital of Wales, Heath Park, Cardiff

SUMMARY Spinal trabecular bone mineral content was measured in the first, second, and thircas lumbar vertebrae by quantitative computed tomography in 88 patients with non-steroid treate $\mathbb{S}_{0}$ rheumatoid arthritis. Results were compared with those obtained in 105 healthy control subjects.o The mean bone mineral content in the patient group, 135.8 (SD 32.8) $\mathrm{mg} / \mathrm{ml} \mathrm{K}_{2} \mathrm{HPO}_{4}$, was。 significantly lower than that in the controls $(151.9(32 \cdot 1) \mathrm{mg} / \mathrm{ml}, \mathrm{p}<0 \cdot 01)$. Division of patients and controls into three age groups showed that the reduction in bone mineral content was mos marked in the youngest age group (21-40 years), the mean value in male patients being significantly lower than in controls $\left(149.6(51.3) \vee 171.7(23.9) \mathrm{mg} / \mathrm{ml} \mathrm{K}_{2} \mathrm{HPO}_{4}, \mathrm{p}<0.05\right)$; ir female patients in this age group the corresponding values were $160(26 \cdot 1) v 178 \cdot 4(22 \cdot 0) \mathrm{mg} / \mathrm{ml}, \vec{\sim}$ $0 \cdot 05<\mathrm{p}<0 \cdot 1)$. No significant difference in mean values between patients and controls was founco in the other age groups. Of the 88 patients, six (7\%) had abnormally low values, defined as bone mineral content $>2$ SD below the normal mean. One vertebral crush fracture was found inp one patient but not in any of the controls. No correlation was found between bone minera content and body weight, duration of disease, or disability as assessed by the London anch Steinbroker methods. These results demonstrate a lower spinal trabecular bone mineral content⿱亠凶禸 in non-steroid treated patients with rheumatoid arthritis than in age and sex matched controls $\stackrel{\Omega}{\rightleftarrows}$ the difference being most marked in younger patients. The finding of abnormally low values ing $7 \%$ of the patients indicates a slightly increased prevalence of spinal osteoporosis in theses patients.

Key word: osteoporosis.

Generalised osteoporosis has been reported in association with rheumatoid arthritis, ${ }^{1-5}$ and there is some evidence that the incidence of vertebral and femoral neck fractures may be increased in such patients. ${ }^{67}$ At present it is unclear whether generalised osteoporosis is a direct consequence of the rheumatoid process or secondary to disease related factors such as steroid treatment ${ }^{3489}$ and inactivity. ${ }^{241011}$ The deleterious effects of steroids on bone mass, particularly in trabecular bone, are well documented, ${ }^{12}{ }^{13}$ but there is some disagreement over whether steroid treated patients with rheumatoid arthritis have more severe bone loss than those not receiving steroids. ${ }^{134 \times 91415}$

Accepted for publication 12 February 1988

Correspondence to Dr J E Compston. Department of Pathology, University of Wales College of Medicine. Heath Park. Cardiff CF4 4XN.
Recently, new techniques have been developed which enable accurate and reproducible measure-o ments of bone mineral content in clinically relevant parts of the skeleton such as the vertebrae and? femoral neck, where osteoporotic fracture mayn occur. ${ }^{16} 17$ When these methods are used osteopor-or osis can be defined as a bone mineral content at the $N$ site of measurement $>2$ SD below the value for age and sex matched controls. In the present study spinal trabecular bone mineral content was meaco sured by quantitative computed tomography in $88{ }^{\circ}$ patients with non-steroid treated rheumatoid arthritis. to establish whether the prevalence of osteoporosis, 0 as defined above, is increased in this disease in the absence of steroid treatment.

\section{Patients and methods}

Eighty eight patients with definite or classical 
rheumatoid arthritis, ${ }^{18}$ who were enrolled into a trial of second line treatment, were studied. Fifty one were female and the mean (SD) age of all patients was $51.7(9.6)$ years (range 26-71). The median duration of disease was four years (range 1-25). None had received systemic steroid treatment at any time, though 14 had received intra-articular steroids. Seventy six patients had erosive disease and 77 patients were seropositive. Most patients were taking one or more of a variety of nonsteroidal anti-inflammatory drugs; in addition, all were receiving second line drug treatment consisting of one of the following: penicillamine (maximum $500 \mathrm{mg} /$ day $)(\mathrm{n}=31)$, hydroxychloroquine $(400$ $\mathrm{mg} /$ day) $(\mathrm{n}=20)$, and auranofin (6 $\mathrm{mg} /$ day) or intramuscular sodium aurothiomalate $(50 \mathrm{mg} /$ month $)$ $(n=37)$. Patients who were housebound or restricted to a wheelchair were excluded from the study as were those with a history of gastrointestinal disease or surgery, liver disease, chronic renal disease, endocrine disease, or known metabolic bone disease. Permission to carry out the study was granted by the local ethical committee. Disability was assessed by the Steinbroker ${ }^{19}$ and the London ${ }^{20}$ methods. The London score ranged from 0 to 3 (median 1.25). Steinbroker assessment placed 11 patients in class 1 , 62 in class 2 , and 15 in class 3 . Control data for quantitative computed tomography were obtained from 105 healthy subjects, 57 female, aged 19-75 years (mean (SD) $45 \cdot 8(13 \cdot 8)$ ).

\section{MEASUREMENT OF SPINAL TRABECULAR} BONE MINERAL CONTENT

Spinal trabecular bone mineral content was measured in the anterior part of the first three lumbar vertebrae by quantitative computed tomography (CT) with a Philips $350 x$ ray CT scanner, using a modification of the method of Cann and Genant. ${ }^{21}$ Patients were positioned with the lumbar spine over a phantom containing tubes of various salt solutions and water. Scans were made through the middle of each vertebra, using a slice thickness of $6 \mathrm{~mm}$, field of view of $400 \mathrm{~mm}$, and tube voltage of $120 \mathrm{kV}$, and the CT number within the vertebral body of L1, L2, and L3 was compared with those of the salt solutions. In this way mineral concentrations were calculated in terms of an equivalent concentration of $\mathrm{K}_{2} \mathrm{HPO}_{4}$ solution, a salt which has radiographic attenuation properties similar to those of calcium hydroxyapatite. The results were corrected for the contribution of non-mineral components to the attenuation coefficient, using calculated values of estimated soft tissue corrections based on published tissue composition data. ${ }^{22}$ The lateral digital pictures of the lower dorsal vertebrae (T11 and T12) and all the lumbar vertebrae in all the patients and controls were examined by a consultant radiologist (CE) for the presence of compression fractures.

\section{STATISTICAL ANALYSIS}

Correlations between continuous variables were examined by linear regression analysis, and the significance of the correlation coefficient was determined by a Student's two tailed $t$ test. Relations between continuous and non-continuous data were examined by two tailed Student's $t$ tests and one way analysis of variance. Differences between patients and controls were tested using an unpaired two tailed $t$ test or, in the case of the $21-40$ year old men, by the Wilcoxon rank sum test.

\section{Results}

When all the patients were considered as one group the mean (SD) spinal trabecular bone mineral content, $135.8(32.8) \mathrm{mg} / \mathrm{ml} \mathrm{K}_{2} \mathrm{HPO}_{4}$, was significantly lower than that in the controls (151.9 (32.1) $\mathrm{mg} / \mathrm{ml}, \mathrm{p}<0.01)$. Six patients, three women aged 50 , 61 , and 64 years and three men aged 39,48 , and 58 years, had abnormally low values, defined as a bone mineral content $>2$ SD below the mean value of age and sex matched controls. Division of female and male patients and controls into three age groups (Figs 1 and 2) showed that the reduction in bone

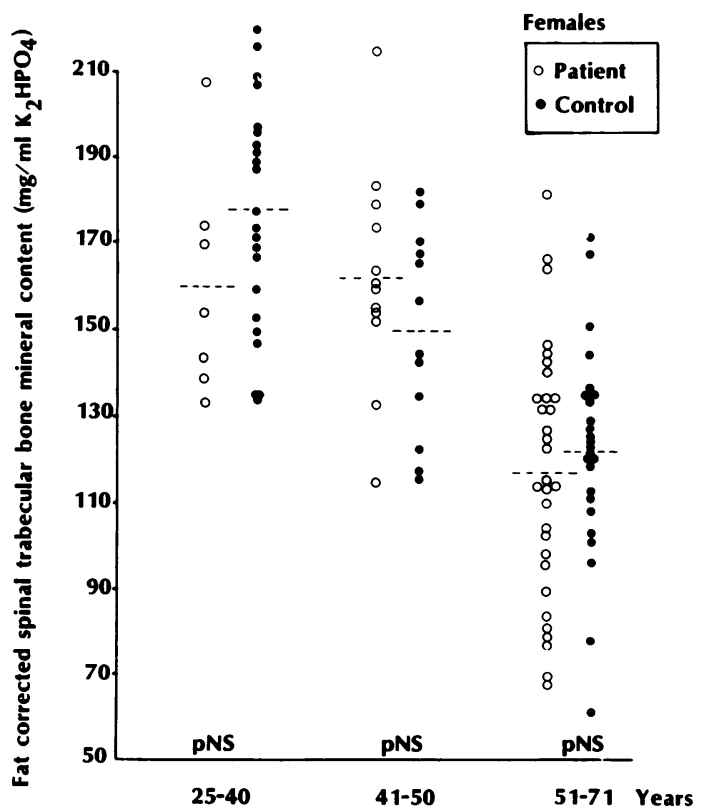

Fig. 1 Fat corrected spinal trabecular bone mineral content in female patients (O) and controls (O) with rheumatoid arthritis. The interrupted horizontal lines indicate the mean value for each group. 
subgroup of these patients the iliac crest trabecular bone volume, assessed histomorphometrically, was reduced in younger patients with rheumatoid arthritis compared with age and sex matched controls, whereas bone volume in older patients was normal. ${ }^{23}$ The results of these two studies therefore suggest that rheumatoid arthritis may be associated with premature bone loss, though the total amount of bone lost during the aging process appears to be similar to that of the normal population; longitudinal studies would be necessary to confirm this.

Previous studies of spinal bone mineral content in rheumatoid arthritis have produced conflicting results. Thus although Sambrook et al reported reduced bone mineral content in the lumbar spine, measured by dual photon absorptiometry, in a total of 84 steroid treated and non-steroid treated patients, ${ }^{24}$ Verstraeten and Dequeker using the same method were unable to demonstrate any reduction in 104 postmenopausal patients ${ }^{7}$; indeed, non-steroid treated patients were found to have a higher spinal bone mineral content than the controls. In the only longitudinal study of spinal bone density in patients with rheumatoid arthritis Sambrook et al were unable to show any increase in the rate of bone loss from the spine in a small group of patients with recent onset, non-steroid treated rheumatoid arthritis. ${ }^{25}$ Only a small number of patients were studied, however, and the follow up period was short.

Total body calcium, which is predominantly a measurement of peripheral cortical bone mass, has also been evaluated in a number of studies. Low total body calcium has been reported in patients with rheumatoid arthritis receiving steroids, ${ }^{9}{ }^{26}$ though this finding has not been invariable ${ }^{27}$; both $\operatorname{low}^{926}$ and normal ${ }^{27-29}$ total body calcium have also been reported in non-steroid treated patients. More localised measurements of radial bone mass, which includes both cortical and trabecular bone, have been made using single photon absorptiometry; most of these studies have reported reduced midshaft ${ }^{50}$ and distal ${ }^{7} 26$ radial bone mineral content in steroid treated patients ${ }^{76}$ and in some cases, in non-steroid treated patients also. ${ }^{726} 3031$ In addition, an increased rate of trabecular bone loss from the distal radius was reported by Sambrook et al. ${ }^{25}$

In the present study only patients not receiving steroids were included so that steroid induced effects on bone mass could be excluded. In this group of patients we were unable to demonstrate any relation between spinal bone mineral content and assessments of functional disability; this may partly be due to the exclusion from our study of patients with severe disability and immobilisation. In addition, a single functional assessment carried out at one moment in time does not take into account either the duration of the disease or its course in the past, both of which are likely to be important determinants of any effects of inactivity on bone. Attempts to correlate disease duration with bone mass have produced conflicting results $^{1} 4$ 10 $14 \quad 3132$; in our study only a weak, nonsignificant, negative correlation was found $(\mathrm{r}=-0 \cdot 111, \mathrm{p} \mathrm{NS})$.

The clinical significance of reduced bone mass associated with rheumatoid arthritis depends on the degree and site of reduction and the changes in bone structure accompanying bone loss. In the final analysis, as fracture is the most important clinical event in osteoporosis, clinical significance is best assessed in terms of the impact, if any, of bone loss on fracture rate. Two studies have indicated that there is an increased risk of osteoporotic fracture associated with rheumatoid arthritis; in one of these this was found only in steroid treated patients, ${ }^{7}$ whereas in the other some increase in fracture risk was found in both steroid and nonsteroid treated patients, though the risk was higher in the steroid users; disability and long duration of disease were also associated with increased fracture rate. ${ }^{6}$ In the present study no significant increase in vertebral fracture rate was found in the patients compared with controls; further studies are required to establish definitely whether or not the incidence of osteoporotic fracture is increased in non-steroid treated patients with rheumatoid arthritis.

This work was supported by the Arthritis and Rheumatism Council of Great Britain and by the Welsh Office. We are grateful to Peter Lewis and Ian Thomas for help with the statistical analysis. We also thank Dr J D Jessop for allowing us to study patients enrolled in the second line drug treatment trial.

\section{References}

1 McConkey B. Fraser G M. Bligh A S. Transparent skin and osteoporosis. Ann Rheum Dis 1965; 24: 210-23.

2 Duncan H. Frost H M. Villanueva A R. Sigler J W. The osteoporosis of rheumatoid arthritis. Arthritis Rheum 1965: 8: 943-54.

3 Saville P D. Kharmosh O. Osteoporosis of rheumatoid arthritis: influence of age. sex and corticosteroids. Arthritis Rheum 1967; 10: $423-30$.

4 Bjelle H O. Nilsson B E. Osteoporosis in rheumatoid arthritis. Calcified Tissue Research 1970); 5: 327-32.

5 Mucller M N. Jurist J M. Skeletal status in rheumatoid arthritis. A preliminary report. Arthritis Rheum 1973; 16: 66-70.

6 Hooyman J R. Melton L J, Nelson A M. O'Fallon W M, Riggs B L. Fractures after rheumatoid arthritis. A population-based study. Arthritis Rheum 1984: 27: 1353-61.

7 Verstracten A. Dequeker J. Vertebral and peripheral bone mineral content and fracture incidence in postmenopausal patients with rheumatoid arthritis: effect of low dose corticostcroids. Ann Rheum Dis 1986: 45: 852-7.

8 Als O S. Christiansen C. Hellensen C. Prevalence of decreased bone mass in rheumatoid arthritis. Relation to anti-inflammatory treatment. Clin Rheumatol 1984: 3: 201-8. 
9 Reid D M, Kennedy N S J, Smith M A, Tothill P, Nuki G. Total body calcium in rheumatoid arthritis: effects of disease activity and corticosteroid treatment. Br Med J 1982; 285: 330-2.

10 Hancock D A. Asiedu-Offei S, Atkinson P J, Reed G W, Wright V. Femoral bone mass in patients with rheumatoid arthritis and osteo-arthrosis. Rheumatology and Rehabilitation 1978; 17: 65-71.

11 Castillo B A, El Sallab R A. Scott J T. Physical activity, cystic erosions and osteoporosis in rheumatoid arthritis. Ann Rheum Dis 1965; 24: 522-6.

12 Curtiss P H, Clark W S, Herndon C H. Vertebral fractures resulting from prolonged cortisone and cortico-trophin therapy. JAMA 1954; 156: 467-9.

13 Hahn T J. Corticosteroid-induced osteopenia. Arch Intern Med 1978; 138: 882-5.

14 Virtama P, Helela T, Kalliomaki J L. Osteoporosis in rheumatoid arthritis. Acta Rheumatologica Scandinavica 1968; 14: 276-84.

15 Hajiroussou V J, Webley M. Prolonged low-dose corticosteroid therapy and osteoporosis in rheumatoid arthritis. Ann Rheum Dis 1984; 43: 24-7.

16 Krolner B, Pors Nielsen S. Measurement of bone mineral content $(\mathrm{BMC})$ of the lumbar spine. 1. Theory and application of a new two-dimensional dual photon attenuation method. Scand J Clin Lab Invest 1980; 40: 653-63.

17 Genant H K, Cann C E, Ettinger B. Gilbert S G. Quantitative computed tomography of vertebral spongiosa: a sensitive method for detecting early bone loss after oophorectomy. Ann Intern Med 1982; 97: 699-705.

18 Ropes M W, Bennett G A, Cobb S, Jacox R. Jessar R A. Proposed diagnostic criteria for rheumatoid arthritis. Ann Rheum Dis 1957; 16: 113.

19 Steinbroker O, Tracger C H, Batterman E C. Therapcutic criteria in rheumatoid arthritis. JAMA 1949; 140: 659-62.

20 Kirwan J R, Reebach J S. Using a modificd Stamford health assessment questionnaire to assess disability in UK patients with RA [Abstract]. Proceedings of the Heberden Society. London. 1982: 22.
21 Cann C E, Genant H K. Precise measurement of vertebraes mineral content using computed tomography. J Comput Assis Tomogr 1980; 4: 493-50).

22 Crawley E O. Evans W D. Owen G M. A correction procedurs for the influence of soft tissue in single energy CT bone mineras measurement. Phys Med Biol (in press).

23 Mcllish R W E. O'Sullivan M M. Garrahan N J. Compston J E Iliac crest trabecular bone mass and structure in patients wit non-steroid treated rheumatoid arthritis. Ann Rheum Dis 1987
46: 830-6.

24 Sambrook P N, Eisman J A, Yeates M G, Pocock N A. Eberl SChampion G D. Osteoporosis in rheumatoid arthritis: safety of low dose corticosteroids. Ann Rheum Dis 1986; 45: 950-3.

25 Sambrook P N. Ansell B M. Foster S. Gumpel J M. Hesp R Reeve J. Bone turnover in early rheumatoid arthritis. 2Longitudinal bone density studies. Ann Rheum Dis 1985; 44. $580-4$

26 Gotfredson A, Als O S, Hassager C. Christiansen C. Bone los in rheumatoid arthritis. In: Ellis K J, Yasumura S, Morgapo W D, eds. In vivo body composition studies. London: Thg Institute of Physical Sciences in Medicine, 1987: 234-8.

27 Kennedy A C, Boddy K, Williams E D, et al. Whole bodg clemental composition during drug treatment of rheumatoid arthritis: a preliminary study. Ann Rheum I) is 1979; 38: 137-40

28 Zanzi I, Roginsky M S. Ellis K J. Blau S, Cohn S H. Skeleta mass in rhcumatoid arthritis: a comparison with forcarm bon mineral content. American Journal of Roentgenology, Radiunton Therapy and Nuclear Medicine 1978; 126: 1305-6.

29 Christiansen C. Rodbro P. Skeletal status in patients witko rhcumatoid arthritis. Acta Med Scand 1975: 198: 453-4.

30 D'Angelo A Fabris A Sartori L et al Mincral metabolism ani bone mineral content in rheumatoid arthritis. Effect of corticee steroids. Clin Exp Rheumatol 1985: 3: 143-6.

31 Oka M. Rekonen A. Kuikka J. Anttinen J. Bone mineri辞 density in rheumatoid arthritis measured by the gamma trans mission method. Scand J Rheumatol 1975; 4: 28-32.

32 Kennedy A C. Lindsay $R$. Bone involvement in rheumatoi $\mathbb{Q}$ arthritis. Clin Rheum Dis 1977; 3: 403-20. 